\title{
La figura emblemática de la melancolía en El sueño de Sor Juana
}

\author{
Jorge Alcázar \\ Universidad Nacional Autónoma de México
}

\section{Introducción}

The common pursuit oftruejudgement.

T. S. Eliot

E ntre los trabajos críticos aparecidos en décadas pasadas en torno al poema magno de Sor Juana, encontramos dos que, aun cuando pudieran parecer divergentes, se complementan mutuamente. En primer lugar, quisiera referirme al ambicioso y ecléctico estudio de Octavio Paz, Sor Juana Inés de la Cruz o las trampas de la fe (1982), que considera-muy al estilo del poeta, con pinceladas amplias y generosas que tienden a producir cuadros sintéticos y generalizadores-varios aspectos de la obra y la vida de la monjajerónima, así como del trasfondo cultural de la Colonia. A este respecto, Paz subraya el carácter sincrético del mundo intelectual que heredó Sor Juana; tanto el que encontró en compendios mitográficos del siglo XVI que buscaban infundir valores morales, y además ofrecían todo tipo de noticias de orden pagano, como el sustrato alegórico con que se racionalizaba el cosmos.

Así Paz habla de una «concepción emblemática del universo,» en la cual (dos jeroglíficos y los emblemas no sólo eran representaciones del mundo sino el mundo mismo era jeroglífico y emblema.» y añade: «Si la realidad del mundo era. emblemática, cada cosa y cada ser era símbolo de otra. El mundo era un tejido de reflejos, ecos y correspondencias» $(1983,221)$. Sirviéndose de las aportaciones historiográficas de Frances Yates, Paz ubica esta concepción 
analógica dentro de la tradición hermética y el neoplatonismo renacentista, la cual desemboca - como indican otros textos pacianos-en el romanticismo y el simbolismo, llegando incluso hasta el siglo XX con el surrealismo.

Al final de su examen de El sueño, al que prefiere seguir denominando Primero sueño, hace una conexión que a primera vista bien pudiera parecer un tanto gratuita. Asocia el poema de Sor Juana con la Męlencolia 1 de Durero. Para Paz, el tema de ambas obras es el mismo: «la contemplación de la naturaleza y la desazón del espíritu-angustia, zozobra, decaimiento, rebeldía-al no poder transformar esa contemplación en forma o idea. El ángel femenino del grabado o. puede pasar por una personificación del alma de Primero sueño, presa de las dudas y el desconsuelo, al final de su aventura espiritual» $(1983,505)$. Como se verá más adelante, Octavio Paz parece ceñirse a la interpretación del grabado propuesta por Erwin Panofsky. Con todo, creemos que vale la pena ahondar en esta intuición del poeta. Sin embargo, a diferencia de él, este texto propone que en el alma del Sueño se encuentran codificados los atributos emblemáticos de la melancolía; y- en vez de seguir a Panofsky--encontramos como más plausible la lectura que ha hecho Frances Yates de la obra de Durero.

El otro trabajo que quisiera mencionar es el ensayo final de Lasfiguraciones del sentido (1984), «El sueño de Sor Juana: alegoría y modelo del mundo,» donde José Pascual Buxó analiza el papel semántico de varias figuras emblemáticas en El sueño. Para esto recupera los comentarios de dos coetáneos de Sor Juana--el franciscano Juan Navarro Vélez y el jesuita Diego de Calleja-y nos demuestra su vigencia crítica, ya que ambos señalan el carácter. alegórico del poema y el uso constante de alusiones recónditas. A continuación contextualiza la idea que se tenía del discurso alegórico recurriendo a los Diálogos de Amor (1535) de León Hebreo, donde se distingue entre sentido literal y varios sentidos alegóricos entretejidos ycopresentes en un texto. Finalmente nos ofrece una lectura de uno de los sentidos alegóricos del Sueño, detallando-con base en las «empresas» de Saavedra Fajardo--el sentido moral de tres de las figuras emblemáticas asociadas con la noche (vv. 25-64): la lechuza, los murciélagos y el búho.

Pascual Buxó no tuvo a bien darnos más ejemplos de los otros niveles de lectura, pero dejó entreabierta la posibilidad de explotar más esta veta de interpretación. Si El sueño es un texto alegórico, habrá pasajes que contengan varias lecturas o líneas de sentido que en primera instancia podrían parecer incompatibles. Posteriormente se indicará otra manera posible de ver a estas aves nocturnas. Mas para ello debemos realizar un largo rodeo. Primero debemos revisar la tradición emblemática y sus modos de codificar el sentido, tratando de no dejar de lado a Sor Juana; después examinar los atributos propios del temperamento melancólico y sopesar dos modos en que se ha interpretado 
el grabado de Durero; sólo entonces podremos acceder de manera cabal al complejo poema barroco en que se sustenta la fama de la Décima Musa.

Sor Juana y la tradición emblemática y mitográfica

An Emblem is but a si/ent parable. Philip Quarles

A diferencia de la visión que tenía Burckhardt de la pintura del Renacimiento, a la que identificó por una tendencia hacia la composición naturalista-opiniól1 seguramente fundada en los juicios de Boccaccio y Vasari (Huizinga 1946, 168)-los historiadores del arte posteriores han sido más cautelosos en sus generalizaciones y han hecho hincapié en la gradual importancia que cobran las imágenes simbólicas en el arte renacentista. Obras tan diversas como la Primavera de Botticelli o la Melancolía de Durero, aúnan a su excelencia técnica un repertorio de alusiones codificadas por las ideas y la literatura de su época. Es más, se podría afirmar que la manera en que estas obras eran «leídas» no difería mucho de cómo se descodificaban los libros de emblemas, como se hará patente en el siguiente apartado.

Los emblemas, según apunta Pascual Buxó, «constituyen una clase de textos sincréticosen los que, por un lado, la 'figura' (o 'cuerpo' del emblema) y el 'mote' ('ánima' o sentencia lacónica, habitualmente en latín) discurren por medios diferentes sobre una misma clase ojerarquía de conceptos» $(1984,245)$. Ernst R. Curtius apunta que a la «figura» y al «mote» también se les conoce como «cifra»y «letra» respectivamente (1955, 1:487). De la conexión establecida entre la imagen y la sentencia se colige el sentido, mismo que a veces se esclarece por un texto o poema adicional que explica el significado de las figuras alegóricas. Por su parte, E. H. Gombrich distingue entre el emblema propiamente dicho--compuesto de imagen, sentencia y versos explicativos-y la divisa (o impresa), formada por una representación icónica y un lema breve (1983, 264). Todas estas distinciones sirven para clarificar la definición que nos ofrece el Diccionario de Autoridades:

se entiende un cierto género de Geroglífico, symbolo o empressa, en que se representa alguna figura o cuerpo de cualquier género o especie que sea, al pie del cual se escriben unos versos, en que se declara el concepto o intento que se encierra en ella: y casi siempre de cosas morales y graves.

A partir de la aparición del Emblematum liber de Andrea Alciato en 1531, el género gozó de gran popularidad. Así lo testifican las sesenta ediciones del libro de Alciato en el siglo XVI y sus múltiples traducciones al francés, inglés, español y aun al mismo italiano. La aportación de Alciato fue la de presentar temas familiares en un lenguaje literario, entresacando sus temas de la historia natural, la fábula y la mitología (Freeman 1948, 38-43). Consecuentemente, los 
libros de emblemas se convirtieron en vehículos ideales para el almacenaje de lugares comunes, la vulgarización de actitudes e ideas y la edificación religiosa.

En la reconstrucción hipotética de la biblioteca de Sor Juana, Octavio Paz le asigna un lugar prominente a los tratados de mitología y emblemática. Entre los que la Madre Juana seguramente conocía-puesto que hay referencias a ellos en el Neptuno alegórico-se pueden mencionar los siguientes: Hieroglyphica (1556) de Pierio Valeriano; el multicitado Mythologice de Natal Conti, publicado por primera vez en Venecia en 1551, que para el año de 1616 contaba con más de quince ediciones en diversas ciudades europeas; Le imagini degli dei degli antichi (1556) de Vicenzo Cartario, mismo que-eomo apunta Alberto G. Salceda en el último tomo de las Obras completas-Sor Juana conocía en una versión latina, la primera de la cuales, apunta Seznec, data de 1581; así como el consabido volumen de Alciato, que seguramente conocía en la versión libre en «rimas castellanas» de Bernadino Daza «el Pinciano» de 1549.

¿Qué tenían en común estos manuales? Sin implicar necesariamente un paso adelante, en relación con sus homólogos medievales-eomo Boccaccio y aun Fulgencio - de los cuales toman prestado a diestra y siniestra, los mitógrafos renacentistas tienen algo en común: no parecen tener mucho sentido crítico, sus descripciones son de origen libresco y en lugar de identificar a las deidades claramente tienden a la confusión. Siguiendo la moda del momento, interesada tal vez en demasía por lo egipcio, le otorgan un lugar prominente a divinidades y figuras orientales: Serapis, Osiris, Horus, Harpócrates, etc. (esto lo encontramos principalmente en Cartario). Como parte de una tradición sincrética-que ya la encontramos desde los tratadistas medievales-yen la cual quedan todavía residuos del paganismo, las deidades grecorromanas se vuelven nebulosas o se les orientaliza. Sin embargo, por otra parte, estos autores presentan ciertas diferencias. Cartario está más interesado en los rasgos iconográficos; a Conti, que se presenta con credenciales de filósofo, le preocupa romper la corteza que rodea las fábulas y penetrar al sentido oculto de los mitos; Valeriano, seguidor de Horapolo, cree-en la procedencia jeroglífica de los emblemas y afirma que no fue por mera casualidad que Pitágoras, Platón y otros sabios recibieran el conocimiento en Egipto (Seznec 1972,229-56; 100 n).

Paz demuestra sagazmente que Sor Juana se vale además de otro compendio, el de Baltasar de Vitoria Teatro de los dioses de la gentilidad (1620). Es el manual español más popular de la época-1legando incluso a eclipsar a la Philosophia secreta (1585) de Pérez de Moya-y cuya aprobación salió de la pluma de Lope de Vega. Lo que hace Vitoria es recolectar material de otras obras similares: francesas (Textor, du Chou!) e italianas (Alciato, Valeriano, Conti y Cartario), precisando en los márgenes las fuentes correspondientes (Seznec 1972, 318). Aun cuando no se le menciona en el Neptuno alegórico, Paz prueba que Sor Juana lo utilizó para trazar la genealogía egipcia del virrey, 
marqués de la Laguna, que hace que Neptuno descienda de Isis y Harpócrates, dios del silencio (1983, 217-18); apelando a la autoridad de Jacobo Bolduc, recurre a una etimología harto extravagante para el caso de Isis: «sabemos que de un nombre hebreo duplicado viene el nombre de Isis. Ese nombre es Is, que significa varón» (231). De manera semejante por lo que toca al Sueño, Paz postula, vía Vossler, que las pirámides de sombra y luz proceden del jesuita Atanasio Kircher (1601-1680), quien a su vez las tomó prestadas, como se aclarará en su momento (485-86).

En Kircher encontramos el último eslabón de la tradición hermética-delineada acuciosamente por Frances Yates-y del entusiasmo egiptológico, del cual emanaron los tres volúmenes del rEdipus mgyptiacus (1652-1654). En el segundo de éstos, Kircher escribiría: «La sabiduría de los egipcios no consistió en otra cosa que esto: el representar la ciencia de la Divinidad y de la Naturaleza bajo diversas fábulas y cuentos alegóricos y de animales y otras cosas naturales» (Godwin 1986,92). Asimismo era conocido en la Nueva España, adonde se carteaba y llegaban sus obras. Sigüenza y Góngora no sólo lo leyó sino que además legó en su testamento su juego de obras para que los jesuitas de la Biblioteca de San Pedro y San Pablo tuvieran el catálogo completo de sus escritos. En el caso de Sor Juana, «la obra de Kircher fue una ventana por la que pudo asomarse a las especulaciones más osadas y a los descubrimientos de la nueva ciencia sin peligro de ser acusada de herejía. A través de Kircher, autor ortodoxo, vislumbró los vastos territorios,que se extendían más allá de las fronteras trazadas por la Iglesia» (Paz 1983,238).

\section{Los emblemas y los modos alegóricos de simbolización}

Befare the knowledge ofletters COD was known by Hierogliphicks. And, indeed, what are the Heavens, the Earth, ney every Creature, but Hierogliphicks andEmblems ofhis Clory? Francis Quarles, Emblems (1635)

En los libros de emblemas desembocan varias tradiciones de simbolización. Los comentaristas de la época creyeron equívocamente encontrar su origen en los jeroglíficos egipcios. Parece ser que con ello no hicieron más que perpetuar las dudosas interpretaciones provenientes de los trabajos históricos de Plinio y Tácito (Montero 1975, 9). Se puede encontrar otro factor influyente en los bestiarios y la literatura alegórica medievales, principalmente en la costumbre de personificar atributos abstractos tales como las virtudes y los vicios así como las artes liberales (Gombrich 1983,216-19). También merecen mencionarse la numismática latina y las modas heráldicas introducidas por los franceses en suelo italiano a finales del siglo XV (Hale 1981, 173).

La parte icónica del emblema se compone de símbolos convencionales. A este respecto, Rosemary Freeman ha comentado un grabado del libro de George 
Wither,A Collection ofEmblems (1635), que muestra a Hércules entre la Virtud y el Placer. La virtud está personificada por un viejecillo barbado que sostiene un libro, tiene el báculo de Mercurio apoyadó sobre una de sus rodillas y un girasol a un lado. Estos tres elementos simbolizan respectivamente el conocimiento, la sabiduría y la constancia en la consecución de un ideal. Su contraparte la representa una mujer desnuda, quien sostiene con una de sus manos una máscara que no alcanza a ocultar los rasgos satánicos de su rostro; con la otra sujeta un látigo; a sus pies hay un laúd; a un lado un jarrón de lirios y una calavera sobre dos huesos entrecruzados. La profesora inglesa hace hincapié en el sentido alegórico de este emblema cuya disposición de motivos carece de cualquier propósito verosimilizante (Freeman 1948, 12-13) (ver Figura 1). Y este será el mismo principio de composición que encontraremos en la Melancolia de Durero: la personificación de una entidad abstracta rodeada de objetos disímiles.

La manera en que un lector coetáneo hubiera descodificado este emblema refleja una actitud muy arraigada en el hombre culto del Renacimiento: su modo alegórico de percibir el mundo. De acuerdo con esta actitud se veía al mundo como la obra de Dios en la que predominaba la abundancia y la variedad. Todo estaba interrelacionado en una escala jerárquica del ser que comprendía desde las cosas insignificantes compuestas de mera materia hasta la divinidad pura e inteligible. Esta actitud se puede ilustrar con aquel tópico, tan extendido en autores medievales y renacentistas, en que se muestra a la naturaleza como si fuera un libro abierto. Curtius ha dedicado un capítulo de su estudió monumental Literatura europeay EdadMedia latina a tratar este tema. Entre los ejemplos que da está uno de fray Luis de Granada tomado de la Introducción del símbolo de lafe.(1582):

¿qué es todo este mundo visible sino un grande y maravilloso libro que vos; Señor, escribistes y ofrecistes a los ojos de todas las naciones, así de griegos como de bárbaros, así de sabios como de ignorantes, para que en él estudiasen todos, y conociesen quién vosérades? ¿Qué serán luego todas las criaturas deste mundo, tan hermosas y tan acabadas, sino unas como letras quebradas y iluminadas que declaran bien el primor y la sabiduría del su autor? (Granada 1984, 31)

De esto a la amalgama de ideas gentiles y religiosas, en la que han insistido estudios recientes, media tan sólo un paso.

En efecto, la postura sincréticadel hombre del Renacimiento lo llevó a creer que la antigüedad clásica y el mundo pagano habían tenido acceso a la revelación cristiana, principalmente a través de la observación del mundo natural y la reflexión filosófica. Esto es patente en estas líneas de un autor inglés del siglo XVII, Sir Thomas Browne: 
Thus there are two books from whence 1 collect my divinity; besides that written one ofGod, another ofhis servantnature, that universal and public manuscript that lies expansed unto the eyes of all: those that never saw him in the one, have discovered him in the other. This was the scripture and theology ofthe heathens ... Surely the heathens knew better how to join and read these mysticalletters than we Christians, who cast a more careless eye on these common hieroglyphics, and disdain to suck divinity from the flowers ofnature. (Religio Medid, Part r, 16)

Aquí nos hemos vuelto a topar con la palabra jeroglífico, por lo que valdría indagar sobre el sentido que tenía en esta época. Según el Diccionario de Autoridades:

Geroglyphico. Expressión del concepto, y lo que se quiere decir, por figuras de otras cosas que se ofrecen a la vista: como la palma lo es de la victoria, y la paloma del candor del ánimo. Los Egypcios fueron los primeros que los inventaron.

Queda claro con lo anterior que jeroglífico alude, según se planteó en el apartado precedente, a la figura (cuerpo o cifra) del emblema, es decir, a la representación visual.

Uno de los iniciadores de la creencia en la estirpe egipcia de los emblemas fue Marsilio Ficino. Esto no nos debe extrañar si tomamos en cuenta que-a través de su versión latina y sus comentarios-logró crear una ola de interés prolongado en el Corpus hermeticum y en su presunta antigüedad que, como se decía, se remontaba a los tiempos de Moisés y los egipcios. En un pasaje, famoso documento de la emblemática, anota Ficino:

Cuando los sacerdotes egipcios deseaban refetirse a los misterios divinos, no utilizaban los pequefios caracteres de los manuscritos, sino las imágenes completas de plantas, árboles o animales; pues Dios tiene conocimiento de las cosas no por vía de pensamiento múltiple, sino por la forma pura y estable de la cosa misma. (Gombrich 1983, 246)

Gombrich ha realizado una brillante exégesis de este pasaje por lo que concierne a su filiación neoplatónica. En primer lugar alude a las dos vías racionales de conocimiento: el raciocinio verbal y la aprehensión instantánea propia de Dios y los ángeles. (Más adelante habrá oportunidad de referirnos con mayor detalle a la psicología renacentista, requisito indispensable para entender a Sor Juana.) Ya Plotino (Enéadas, V, 8) había indicado algo semejante cuando señalaba que los egipcios no usaban letras:

sino que figuraron los objetos porjeroglificos y designaron simbólicamente cada 'Uno de ellos por un emblema particular en sus misterios; así, cada jeroglífico constituía una especie de ciencia o sabiduría y presentaba las 
cosas ante la vista de una manera sintética, sin concepción discursiva o análisis. (Plotino 1980,342-43)

Esta idea, en conjunción con otra creencia neoplatónica-la inspiración divina (jurare divino -tuvo como efecto el de privilegiar la imagen sobre el lenguaje verbal en cuanto que se pensaba que era un vehículo más propicio para comunicar las verdades eternas. Ficino sostenía que en los escasos momentos de inspiración divina el hombre podía ascender a sus orígenes: al ámbito de las formas platónicas y las ideas arquetípicas. Creía que en estas experiencias de éxtasis inefables-propias del «entusiasmo» amoroso, poético, profético o religioso-la mente, «viendo con un ojo incorpóreo,» «se libera a sí misma, no solo del cuerpo, sino también de los sentidos y de la imaginación,» y de esta manera se transforma en un «instrumento de lo divino» (Panofsky 1972, 199).

Las opiniones de Plotino y Ficino dan pie para pensar que en los símbolos de los emblemas hay latente un sentido místico ulterior. En esa direccción apunta la concepción renacentista que equipara el emblema con el jeroglífico. Los tratadistas y comentaristas--desde el legendario Horopolo a Giordano Bruno-parecen presuponer que el jeroglífico es el signo de una notación sagrada, casi se antojaría decir: la escritura de Dios.

Sor Juana no era ajena a esta conceptualización de la emblemática, ni a la visión sincrética que hermanaba lo pagano y lo cristiano; ni tampoco dejó de sucumbir ante el encanto hermético de lo egipciano.! Así, en el inicio del Neptuno alegórico, esta vez apelando a la autoridad de Valeriana, nos plantea algo que nos sonará a estas alturas bastante familiar:

Costumbre fue de la antigüedad, y muyespecialrnente de los egipcios, adorar sus deidades debajo de diferentes jeroglíficos y formas varias: y así a Dios solían representar en un círculo, como lo escribe Pierio Valeriano: oo. No porque jusgazen que la Deidad, siendo infinita, pudiera estrecharse a la figura y término de cuantitud limitada; sino porque, como eran cosas que carecían de toda forma visible, y por consiguiente, imposibles de mostrarse a los ojos de los hombres (1os cuales, por la mayor parte, sólo tienen por empleo de la voluntad el que es objeto de los ojos), fue necesario buscarles jeroglíficos, que por similitud, ya que no por perfecta imagen, las representasen. (Sor Juana 1957, 355-56)

Una idea semejante encontraremos en El sueño, cuando a las Pirámides se les vea como «señales exteriores / de las que, dimensiones interiores, especies son del alma intencionales» (vv. 401-404). De vuelta al Neptuno, Sor Juana recalca la función recóndita de los emblemas ya que nos sirven para «no vulgarizar sus misterios a la gente común e ignorante,» citando en latín un versículo de los Salmos, que es el mismo que Valeriano usa en la dedicatoria a Cosme de Medici de su Hieroglyphica: 
«'1 will open my mouth in a parable; 1 will utter dark sayings of old' (Psalm

78 , v. 2). What else did He want to say than that His language be hieroglyphic and He voice the ancient records allegorically.» (Wittkower 1977, 128)

Teniendo presente de qué manera se inserta Sor Juana Inés de la Cruz dentro de la tradición emblemática, pasemos al siguiente eslabón de la hipótesis aquí esbozada.

\section{La revalorización renacentista del temperamento melancólico}

Parióme mi madre una noche escura cubrióme de luto, faltóme ventura.

La teoría de los humores divide al carácter humano en cuatro temperamentos: el sanguíneo, el colérico, el flemático y el melancólico. Los sanguíneos son activos, optimistas, exitosos y se interesan por las cosas mundanas; los coléricos se caracterizan por ser irritables y propensos a reñir; los flemáticos son tranquilos y un tanto letárgicos; mientras que los melancólicos tienden a ser tristes, pobres, fracasados y condenados a ocupaciones serviles (Yates 1982, 93). Dentro del esquema totalizante de la época, a cada temperamento se le asocia con un elemento y, por ende, con la fusión de dos cualidades físicas, a la vez que se le coloca bajo la influencia de un planeta y su metal respectivo. Las correspondencias de cada complexión pueden resumirse así:

\begin{tabular}{|c|c|c|c|c|}
\hline Temperamento & Elemento & $\begin{array}{l}\text { Combinación } \\
\text { de cualidades }\end{array}$ & Planeta & Metal \\
\hline Sanguíneo & Aire & $\begin{array}{l}\text { o contrarios } \\
\text { (caliente-húmedo) }\end{array}$ & Júpiter & Estaño \\
\hline Colérico & Fuego & (caliente-seco) & Marte & Hierro \\
\hline Flemático & Agua & (frío-húmedo) & Luna & Plata \\
\hline Melancólico & Tierra & (frío-seco) & Saturno & Plomo \\
\hline
\end{tabular}

En este modelo jerárquico-vigente durante la Edad Media y parte del Renacimiento-el escaño más bajo le correspondía al temperamento melancólico. Así en el Corbacho, encontramos la siguiente descripción:

Ay otros ombres que son malencónicos: a estos corresponde la tierra, que es el cuarto elemento, la cual es fría y seca. Estos tales son ombres muy irados, sin tiento ni mesura. Son muy escasos en superlativo grado; son incomportables, donde quiera que usan, mucho riñosos e con todos rifadores. Non tienen temprança en cosa que fagan sinón dar con la cabeça a la pared. Son muy inicos, maldizientes, tristes sospirantes; fuyen de todo lagar de alegría; non les plaze ver ombre que tome solaz con un paperote. Son sañudos, e luego las puñadas en la mano, porfiados, mentirosos, engafiosos; e inumerables otras tachas e males tienen. (Martínez de Toledo 1981,208-209) 
Este retrato nada halagüeño prevaleció hasta entrado el siglo XVI. Todavía en la lírica popular de esa época nos podemos topar con coplas como éstas, extractadas del cancionero Flor de enamorados (1562):

$$
\begin{aligned}
& \text { ¡Apartáos de mi, } \\
& \text { bien afortunados, } \\
& \text { que de sólo verme } \\
& \text { seréis desdichados! } \\
& \text { Dijeron mis hados } \\
& \text { cuando fui nacido } \\
& \text { si damas amase, } \\
& \text { fuese aborrecido. } \\
& \text { Fui engendrado } \\
& \text { en signo nocturno; } \\
& \text { reinaba Saturno } \\
& \text { en curso menguado. } \\
& \text { Mi lecho y la cuna } \\
& \text { es la dura tierra; } \\
& \text { crióme una perra, } \\
& \text { mujer no ninguna. } \\
& \text { (Frenk } 1966 \text { 134) . }
\end{aligned}
$$

Sin embargo, para estas fechas en los círculos cultos y cortesanos ya prepondera otra concepción del melancólico. Aun cuando todavía conserva varios de sus rasgos propios, el acento está en. otra parte: en el conocimiento y la búsqueda trascendente. Consideremos por un momento el cuadro de este temperamento en Minerva Brittana (1610) de Henry Peacham (ver Figura 2). Ahí se puede observar a un hombre estudioso y solitario, sentado en un banco enmedio de un bosque, flanqueado por dos criaturas ominosas que evitan la luz: un búho y un gato. El equivalente emblemático de estos animales nocturnos, en el grabado de Durero, lo será el murciélago cuyas alas sirven de título a la obra. Al igual que el ángel de ésta, el hombre del emblema tiene un libro sobre el regazo. En el texto de Peacham se lee además:

His mouth, in signe of silence, up is bound,

For Melancholly laves not many words:

One foote oo Cube is fixt upoo the ground,

Thewhich him plodding Constancie affordes:

A sealed Purse he beares, to shew no vice,

So proper is to him, as Avarice.

(Kermode y Hollander 1973, plate 18)

Estas tres características, el silencio, la constancia y la parsimonia, están asimismo presentes en la Melancolia de Durero. A la mujer alada la rodea un 
silencio reflexivo. El compás que sostiene es también conocido como símbolo alegórico de la constancia (Freeman 1948, 146). Y al igual que el varón del emblema, ella tiene una bolsa de dinero cerrada, indicativa del desapego por las cosas materiales que a veces raya en la avaricia (ver Figura 3).

Este viraje en la conceptualización del melancólico es lo que registra en sus páginas Saturno y melancolía (1964). Klibansky, Panofsky y Saxl, los autores de esta obra erudita y casi enciclopédica, han trazado el paso de una visión pesimista medieval, asociada con la acedia, a una que se desprende del humanismo florentino y que rehabilita, a partir de un texto pseudoaristotélico (Problemataphysica), al temperamento melancólico, equiparándolo con varios tipos de genialidad. Ficino fue la figura clave en esta revalorización, ya que «fue el primer autor que identificó lo que 'Aristóteles' había llamado la melancolía de los hombres intelectualmente sobresalientes con el 'furor' divino de Platón.» Así, en De vita triplic, afirma que la bilis negra, el humor dominante en la complexión melancólica,

obliga al pensamiento a penetrar y explorar el centro de sus objetos, porque la propia bilis tiene afinidad con el centro de la tierra. De la misma manera eleva el pensamiento a la comprensión, porque corresponde al más alto de los planetas. (Klibansky et al. 1991,254)

Ficino, como buen melancólico, tenía conciencia de que era necesario templar la severidad saturnina con influencias joviales y mundanas propias del sanguíneo gobernado por Júpiter. Así, atrás del ángel del grabado de Durero, podemos observar un cuadrado mágico, cuyo juego numérico-que en todas direcciones suma 34 (es decir 7)-Está calculado para atraer los influjos de este planeta (ver Figura 3). De manera semejante, la contraposición entre los temperamentos melancólico y sanguíneo (y por ende, los atributos simbólicos asociados con ellos, como Saturno/Júpiter, introversión/extraversión, noche/día, etc.) se refleja en el contraste de la composición cerrada y abierta, que circunda respectivamente a las estatuas de Lorenzo y Giuliano de Médicis esculpidas por Miguel Ángel. Semejante a la oposición dialéctica que se encuentra en la pareja de poemas «L'Allegro» y «11 Penseroso» de Milton, de estas dos obras de la Capilla Médicis Giuliano representa al tipo jovial y activo, «abierto al mundo,» mientras que Lorenzo es el saturnino contemplativo, retraído hacia sí mismo. Como dice Pico de la Mirandola en su Comentario a Benivieni: «Saturno significa la naturaleza intelectual que se aplica y atiende a la comprensión y contemplación. Júpiter significa la vida activa que consiste en inspeccionar, administrar y mantener en movimiento con sus normas las cosas que están sujetas a ella o.. Saturno produce hombres contemplativos, mientras que Júpiter les da principados, gobiernos y la administración de los pueblos (Panofsky 1972,275). Por lo que toca a la estatua de Lorenzo de Médicis (ver Figura 4), Erwin Panofsky añade lo siguiente. 
Como el rostro de la Melencolia de Durero, la cara del Pensieroso está oscurecida por una grave sombra que sugiere lafacies nigra del Saturniano melancólico. El dedo índice de su mano izquierda cubre su boca con el gesto del silencio satumiano. Su codo descansa en un cofrecillo cerrado, un símbolo típico de la parsimonia de los satumianos; y, para hacer el simbolismo todavía más explícito, la parte delantera de este cofrecillo está adornada con la cabeza de un murciélago, el animal emblemático del grabado de la Melencolia 1 de Durero. (Panofsky 1972, 276)

\section{La reinterpretación de Frances Yates de la Melancolía de Durero}

There is a kindly mood olmelancholy,

That wings the soul andpoints her ro the skies. John Dycr

Parece ser, sin embargo, que la fuente principal de Durero no proviene de Ficino sino de la versión manuscrita de 1510 del tratado de Cornelio Agripa De occulta philosophia (publicado. por primera vez en 1533). Agripa alude a la teoría pseudo-aristotélica que mencionamos antes:

Cuando se enciende ,y brilla, el humor melancholicus genera un frenesí (furor) que nos lleva a la sabiduria ya la revelación, especialmente cuando se combina con una influencia celeste, sobre todo la de Saturno. (Yates 1982, 97)

Agripa además ofrece una novedosa explicación de este fenómeno. La bilis negra tiene la propiedad de atraer ciertos «demonios» (entiéndase espíritus) 'que, en correspondencia con la triple capacidad del alma, generan tres tipos de melancolía inspirada. La acción de los demonios inferiores sobre la imaginación (imaginatio) induce a la habilidad artística. Cuando los espíritus medios actúan sobre la razón (ratio) propician el conocimiento de las cosas naturales y humanas. Por último, cuando la actividad del alma se concentra sobre el intelecto (mens), los demonios superiores actúan sobre la mente revelando los secretos de las cosas divinas. (Yates 1982,97)

Yates cree que la obra de Durero representa el primer tipo: la melancolía del artista plástico inspirado. El grabado lo domina una figura femenina alada. $\mathrm{Su}$ tez morena (facies nigra) es un síntoma de la acción de la bilis sobre su constitución. Apoya la cabeza, en actitud pensativa, sobre la mano izquierda, rasgo distintivo-como y a hemos visto-del melancólico; mientras que la derecha sostiene un compás y descansa sobre un libro. Está rodeada por instrumentos artesanales y de medición y a los pies tiene una bolsa de dinero, lo cual hace ostensible los atributos de aquellos individuos que gobierna Saturno: habilidad para medir y contar. (Yates 1982,94 ) 
Hasta aquí Frances Yates se ha beneficiado de la erudición iconológica que despliega Panofsky en su análisis de la obra de Durero. Mas a ella no parece convencerle la interpretación romántica que ofrece de la misma. Él opina que el grabado representa la frustración del genio inspirado que cae en una melancólica inactividad producida por el sentimiento de fracaso y de impotencia, opinión a la que--eomo indicamos al inicio de este trabajo--Octavio Paz parece adherirse. por el contrario, para Yates el ángel «no se encuentra en un estado de inactividad depresiva, sino en un intenso trance visionario» (1982, 102). Consideremos los elementos que la conducen a hacer este planteamiento.

El primer indicio de un estado de exaltación contemplativa es el perro escuálido que yace a un lado de la mujer, el cual Panofsky considera simplemente como animal típico de Saturno. Para Yates representa los sentidos corporales, exhaustos y rigurosamente controlados, según el comentario de la fábula de Acteón de Natalis Comis (como también se conocía a Natal Conti) del ya referido Mythologice, IV, xxiv $(1982,103)$. Yates cita unos versos del $<\mathrm{dl} \mathrm{Penseroso»de} \mathrm{Milton} \mathrm{que} \mathrm{intertextualmente} \mathrm{arrojan} \mathrm{luz} \mathrm{sobre} \mathrm{el} \mathrm{mismo}$ tema. En esta obra, el poeta se dirige a la oscura diosa de la Melancolía $(<<$ thou Goddess sage and holy / ... Whose saintly visage is too bright / To hit the sense of human sight»), descendiente de 'Saturno, a quien ruega lo ilumine en sus empresas intelectuales.
Or let my lamp at midnight hour
Be seen in some high lonely tower, Where 1 may oft outwatch the Bear, With thrice great Hermes, or unsphere The spirit ofPlato to unfold What worlds or what vast regions hold The immortal mind that hathforsook Her mansion in thisfleshy nook. (vv., 85-92; el énfasis es mío.)

Aunada a la trascendencia de lo corpóreo, otra clave importante del grabado lo representan las alas de la figura. ¿Será semejante al querubín de la contemplación (《<The Cherub Contemplation,» v. 54) del poema del Milton? Séalo o no, es un indicio claro del propósito de elevación, dentro del marco de referencia de la época, hacia las zonas de las inteligencias que dirigen el curso de las esferas celestes y las jerarquías angelicales que rodean a Dios.

La escalera representa los peldaños de los grados de la creación (mismos que encontraremos en el poema de Sor Juana), cuyo ascenso conduce a la unión con la divinidad. Yates la asocia con la escala de Jacob por la que suben y bajan los ángeles. Se encuentran representaciones análogas en'las obras de Robert Fludd (ver Figura 6)--de quien hablaremos más adelante-yen la literatura alquímica, en donde las etapas del proceso tranfonnativo se simbolizan por 
medio de una escalera que lleva a la piedra filosofal, la cual, en sus versiones más refinadas, no es más que un estado de integración psíquica o una entidad mística (Jung 1980,232-41).2

Finalmente, tenemos la figura emblemática del arcoiris. Su equivalente en el simbolismo alquímico lo representa la cola del pavo real (cauda pavonis), cuyo color blanco contiene todos los colores, meta del proceso alquímico que abarca desde el primer nigredo-que se asocia con el estado inicial de la materia: el caos (masa confusa)- hasta el albedo de la etapa final (Jung 1980, 228-32). En la emblemática religiosa, el arcoiris designa la paz interior del creyente cuya devoción meditativa lo coloca en una situación de armonía con el mundo y lo divino (Freeman 1948, 183-85). En ambos casos es un signo de síntesis e integración. En el caso del grabado de Durero, la elevación es-según la lectura de Frances Yates-hacia los confines nocturnos de la inspiración plástica. Como apunta la historiadora inglesa, el «melancólico saturnino 'se hádespedido de los sentidos' y está volando muy alto en mundos más allá de los mundos, en un estado de trance visionario» $(1982,103)$. En el último apartado de este ensayo se intentará señalar de qué manera algunos de los elementos aquí tocados reaparecen en el poema de Sor Juana.

\section{La melancolía inspirada en Elsueño de Sor Juana}

it is not a melancholy conceit to think we are al! asleep in this world. and that the conceits ofthis life are as. mere dreams to those of the n,ext. as the phantasms of the night to the conceits of the day. There is an equal delusion in both. and the one doth but seem to be the emblem or picture of the other: we are somewhat more than ourse'lves in our sleeps. and the slumber of the body seems to be but the waking ofthe soul. It is the ligation ofsense. but the liberty of reason; and our waking conceptions do not match the fandes or our sleeps.

Sir Thomas Browne

En primer lugar quisiera hablar del procedimiento discursivo que sigue Sor Juana, y en virtud al cual los referentes textuales del poema permanecen en una especie de penumbra nebulosa. Ya aludimos a las «censuras» de Juan Navarro y Diego de Calleja, donde ponderan las alusiones recónditas (el «grande golfo» de erudiciones y sutilezas) y la naturaleza alegórica de la obra. A Pascual Buxó, como indicamos al principio, le correspondió desentrañar el sentido moral de tres de las figuras emblemáticas asociadas con la noche: la lechuza, los murciélagos y el búho. Yo quisiera señalar un hecho trivial. A estas aves nocturnas nunca se les designa de manera directa, sino por epítetos y descrip- 
ciones artificiosas: «la avergonzada Nictimene» (v. 27); «las atrevidas Hermanas» (v. 58) que desobedecieron a Baca, quien a cambio «les dio pardas membranas;» «el parlero / ministro de Plutón» (vv. 53-54). De esta manera Sor Juana se las ingenia para hablar de las aves nocturnas sin nombrarlas directamente, y, a la vez, aludir a lo que una persona culta como ella podría saber, si conociera las Empresas de Saavedra Fajardo y las Metamorfosis de Ovidio.

En este singular proceder referencial se puede hallar una de las claves para mejor comprender el vasto poema de Sor Juana. Si Pascual Buxó está en lo correcto en cuanto que hay varios niveles de sentido entreverados, el inicio del Sueño, por ejemplo--en que la sombra de la noche asciende hacia el orbe lunar-podría aludir también a algo más.

\author{
PIRAMIDAL, funesta, de la tierra \\ nacida sombra, al Cielo encaminaba \\ de vanos obeliscos punta altiva, \\ escalar pretendiendo las Estrellas; \\ (vv., 1-4; todas las referencias son a la edición de Méndez \\ Plancarte 1951)
}

Ese algo más es nada menos que el alma cuando se encuentra en lo más alto del orbe, a punto de traspasar el cerco lunar. Con esto estoy sugiriendo que $E l$ sueño, como buena epopeya del entendimiento humano, comienza in medias res. Al señalar el «estilo oo. heroico» del poema, Navarro Vélez no estaba nada equivocado. No creo que Paz se refiriera a esto cuando dijo, no sin acierto, en lugar escondido de su libro, que el poema es una épica del espíritu (1983,485 n).

La clave indicial de tal aseveración se encuentra en la primera palabra del poema: piramidal. La clarificación estructural de este monema hay que ubicarla hasta los versos 412-34:

Estos, pues, Montes dos artificiales

(bien maravillas, bien milagros sean),

[las pirámides egipcias ...]

si fueran comparados

a la mental pirámide elevada

donde-sin saber cómo-colocada

el Alma se miró, tan atrasados

se hallaran, que cualquiera

gradüara su cima por Esfera:

pues su ambicioso anhelo,

haciendo cumbre de su propio vuelo,

en la más eminente

la encumbró parte de su propia mente,

de sí tan remontada, que creía

que a otra nueva región de sí salía. 
Aquí cabe señalar la equivalencia semántica de expresiones como «ambicioso anhelo» (v. 429) con «de vanos obeliscos punta altiva» del inicio del poema (v. 3); o de «que cualquiera / gradüara su cima por Esfera» (vv. 427-28) y «que creía / que a otra nueva región de sí salía» (vv. 433-34) con «al superior convexo aun no llegaba / del orbe de la Diosa / oo. tres veces hermosa» (vv. 12-14).

Lo anterior, creo, aclara la palabra inicial del texto. Sigamos adelante. Notemos la ambigüedad sintáctica de los dos primeros versos: «Piramidal, funesta, de la tierra / nacida sombra.» ¿Por qué funesta? Aun cuando el alma racional sea la parte más encumbrada del ser humano está irremediablemente condenada a habitar el mundo sublunar. Solamente se puede librar de la prisión corpórea durante el sueño.

A condición de abundar más al respecto, tal vez sería conveniente hacer un . paréntesis para resumir la estructura medieval del ser humano, misma que con ligeras variantes todavía tenía vigencia en el siglo XVII. Se divide en tres partes: a) el alma vegetativa que comprende los procesos de nutrición, crecimiento y reproducción;(b) el alma sensible consta de diez sentidos, a saber: i. los cinco sentidos externos, por todos conocidos, y ii. los sentidos interiores: el sentido común, la apreciación o estimativa, la imaginación, la memoria y la fantasía; c) el alma racional dividida èn razón y en intelecto (Lewis 1980, 124). Sor Juana hace referencia a esta disposición, tripartita cuando al señalar que el alma (racional) se eleva sobre el águila, jerarca de las aves, (vv. 327-34), comenta de pasada:

\section{A la región primera de su altura (ínfIma parte, digo, dividiendo en tres su continuado cuerpo horrendo)}

Es «ínfima parte» porque el alma racional corona la punta de la pirámide mental, mientras que las otras dos almas forman el resto del «cuerpo horrendo» (anima secunda en la clasificación de Ficino), sujeto a la mutabilidad yel devenir. No está de más tener presente que, dentro de esta cosmovisión, el ser humano es el gozne entre los ángeles y las bestias ( $c f$ vv. 690-95).

Tanto en este pasaje, como en otros del texto, se puede percibir una marcada filiación neoplatónica. Esto se hace patente desde los primeros versos: «de la tierra / nacida sombra.» El ser humano, en tanto que habitante del mundo de las apariencias, no es más que una sombra, un mero simulacro de las formas puras, las ideas platónicas. Méndez Plancarte en su versión en prosa convierte a la «sombra fugitiva» del verso 9 en «Sombra impalpable, 'fugitiva' ante el tacto» (Sor Juana 1951, 603). En cuanto ser inmaterial el alma es impalpable. No obstante, hay que tomar «fugitiva» en su sentido literal, el alma se ha escapado de la cárcel del cuerpo: 
La cual, en tanto, toda convertida a su inmaterial ser y esencia bella,

y juzgándose casi dividida

de aquella que impedida

siempre la tiene, corporal cadena,

que grosera embaraza y torpe impide

el vuelo intelectual

(vv. 292-301)

Otro elemento de la cita de las pirámides en el que vale la pena detenerse es la fusión metonímica del ascenso de la entidad intelectiva del alma y su posición en la cima de la «mental pirámide:»

haciendo cumbre de su propio vuelo, (v. 430)

Este uso del lenguaje figurado es, en términos del entramado global del poema, equivalente a otros versos del principio:

quedando sólo dueño

del aire que empañaba (vv. 16-17)

Resumiendo lo dicho hasta aquí. Los primeros versos del Sueño hacen referencia a los vanos intentos del Alma, así como de la sombra nocturna (el ser sombría es un atributo adicional que-como veremos a continuación-acompaña al alma en la gran noche del conocimiento) por escalar las estrellas. Sor Juana muy hábilmente oculta a aquélla fundiéndola en ésta. y casi se antoja decir que la «cifra» en la manera en que presenta el avance gradual del «imperio silencioso» de la noche.

Hay varias razones que pudieron haber propiciado esto. Sor Juana tal vez contaba con la familiaridad del hombre letrado con la tópica visual que aparece en los libros de empresas de Saavedra Fajardo o las obras de Kircher. El polígrafo jesuita tomó el motivo de las pirámides de luz y sombra de Robert Fludd (Godwin 1986,41). Según Fludd existe interpenetración entre las cualidades del espíritu y la materia que se pueden simbolizar por ambas pirámides. En lo más alto del empíreo domina la luz, mientras que en las profundidades del reino elemental encontramos lo pesado, lo denso y lo opaco en grado sumo (Godwin 1979,43) (ver Figura 5).

Esta interpenetración está implícita en la forma del poema. Ya José Gaos había hablado de la «simetría perfecta» del poema, en el que sus «partes se ordenan en torno de un centro (el sueño) a cuyos extremos se hallan la media noche y el amanecer, y, entre el centro y los extremos, el dormir y el despertar» (Pascual 1984, 239). Si retomamos a la posición estructural de la «sombra fugitiva,» notaremos que vuelve a aparecer (v. 882) hacia el final de la sección que pormenoriza el despertar del cuerpo dormido (vv. 868-86). En este contexto 
se le asocia con la linterna mágica y, por 10 tanto, con las fingidas figuras $(<<$ las fantasmas») de la fantasía, la facultad interior que--eomo se hará patente más adelante-incide más sobre el temperamento melancólico.

Si se acepta esta lectura que-apoyándose en los paralelismos estructurales observables en el texto-propone una amalgama casi perfecta entre el alma racional y la sombra de la noche, 10 que se va a plantear a continuación parecerá menos excéntrico. Al alma se le personifica como la melancolía inspirada. Su «atezado ceño» (v. 11) recuerda lafacies nigra del saturnino reflexivo. Encontramos de nuevo el impulso áscendente hacia los cuerpos celestes:

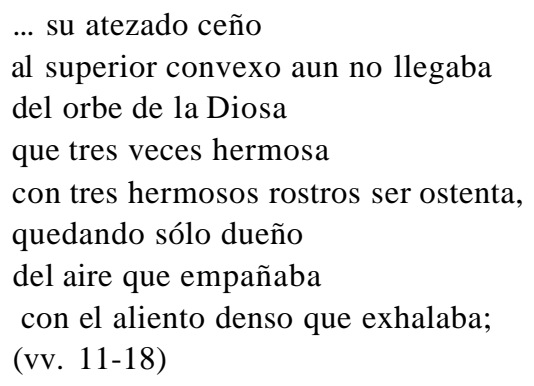

Se rodea de las criaturas emblemáticas que repudian la luz y se asocian con el temperamento melancólico: la lechuza, los murciélagos y el búho (vv. 25-64). Otro animal del mundo inferior que aparece en este tapiz alegórico es el pez (vv. 89-93), dos veces mudo, a quien se le asocia con el silencio y la oscuridad. En otro poema que trata de la oscura noche del conocimiento, The Shadow of Night de George Chapman, también se le encuentra (Yates 1982, 237). Harpócrates, «con indicante dedo» (v. 75), trae a la mente la análoga posición de la estatua pensativa de Lorenzo de Médicis. No falta «el can dormido» (v. 80) y la referencia a la metamorfosis de Acteón acosado por sus propios perros (vv. 113-22), que, como se apuntó antes, simbolizan los sentidos dormidos. Es más, para la interpretación renacentista de esta historia, Frances Yates--eomo se recordará-apela a la autoridad de un mitógrafo, Natal Conti, a quien Sor Juan conocía ampliamente.

Un teórico de los humores, Thomas Walkington, definió a la melancolía como «un dulce sueño de los sentidos» (Yates 1982, 103). Lo cual es muy semejante a estos versos del Sueño:

así, pues, de profundo

sueño dulce los miembros ocupados,

quedaron los sentidos

del que ejercicio tienen ordinario

(vv. 166-69). 
Estas figuras emblemáticas preludian simbólicamente la relación detallada del sueño fisiológico que termina con la presentación jerárquica ascendente de los sentidos interiores. ${ }^{3}$

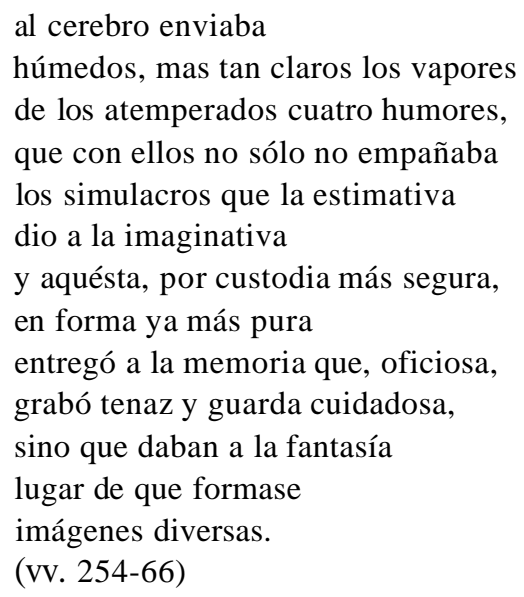

A la fantasía, la facultad más alta del alma sensible, se le compara con el Faro de Alejandría, «cristalino portento,» por su capacidad de copiar las imágenes de todas las cosas:

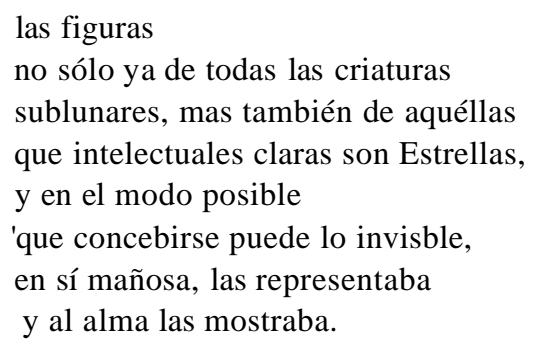

La actividad catalizadora de la fantasía libera al alma de la «corporal cadena» (v. 299) y la induce al «vuelo intelectual» (v. 301) por los confines céléstes. Esta propiedad de la fantasía en estados de exaltación es rasgo privativo del temperamento melancólico, según nos dice Robert Burton, quien por cierto reduce los sentidos interiores a tres (sentido común, memoria y fantasía) y no ve diferencia alguna entre esta última y la imaginación.

In time ofsleep this faculty [phantasy] is free, and many times conceives, strange, stupend, absurd shapes, as in sick men we commonly observe. His organ is the middle cell of the brain; his objects all the species cornmunicated to him by the common sense, by comparison of which he feigns infmite other unto himself. In melancholy men this faculty is more pov arful and strong ... In poets and painters imagination forcibly works as appears by their 
several fictions, antics, images: as Ovid's house of Sleep, Psyche's palace

. in Apuleius, etc. (Burton 1932, 1: 159-60)

Esta conexión natural entre el espíritu melancólico y la fantasía no era extraña ni para el mundo hispano ni para Sor Juana. Por ejemplo, en El mágico prodigioso de Calderón se puede encontrar lo siguiente:

$\quad$ Formando
cuerpo de tu fantasía
el hombre debió ser;
que tu gran melancolía
le supo formar y hacer
de los átomos del día.
(3a.Jornada, vv. 2373-78)

Sor Juana por su parte se hace eco de esta asociación en el Auto historialalegórico de San Hermenigildo, en el que Leovigildo le pide a la Fantasía que se identifique y ella responde así:

La imagen de tu propia Fantasía, que en ella impresa estoy tan vivamente, que parezco aparente cuerpo, que de aire forma vapor craso, pues la imaginación suele hacer caso; y más ahora, con la conveniencia que a alegóricos entes da licencia, sin violar a la Historia su pureza, pues no añade ni quita a su entereza el que, suspenso en tu melancolía, a ti te hable tu propia Fantasía.

(Sor Juana 1955, 143)

En El sueño, el vuelo nocturno de la «sublunar Reina soberana» (v. 439) se divide en dos etapas cuyos rumbos dependen de la directriz de las dos facultades del alma racional. En la primera, que Méndez Plancarte ha denominado «La derrota de la intuición» (vv. 412-559), el alma posa «sus intelectuales ojos» sobre «el inmenso agregado» del cosmos que rebasa su capacidad de comprensión. En esta etapa, la «facultad intelectiva» (v. 482) actúa como guía del alma, que por «mirarlo todo, nada vía» (v. 480). El intelecto es la facultad superior del alma racional y es el elemento que semeja al hombre con las criaturas angélicas. Tal vez sea pertinente recordar lo que el arcángel Rafael le dice a Adán, en Paradise Lost, cuando lo instruye sobre las cosas del mundo:

the Soule

Reason receives, and reason is her being,

Discursive or Intuitive; discourse

Is ofiest yours, the latter most is ours, 
Differring but in degree, ofkind thesame.

(Libro Y, vv. 486-90)

De esto se desprende que el intelecto (intellectus) es intuitivo y la razón (ratio) discursiva. Santo Tomás es aún más' explícito en lo que toca a la relación de ambas facultades.

el intelecto (intelligere) es la comprensión simple (es decir, indivisible, no compuesta) de una verdad inteligible [a esta facultad apelan los jeroglíficos según Ficino y Plotino], mientras que razonar (ratiocinari) es la progresión hacia una verdad inteligible pasando de un aspecto entendido (intellecto) a otro. Así, pues, la diferencia entre ellas es como la diferencia entre el descanso y el movimiento o entre la posesión y la adquisición. (Lewis 1980, 120)

El alma, con la «mañosa» cooperación de la fantasía, se ha encumbrado tan alto que pareciera semejante a los ángeles cuando en realidad no 10 es. Prueba de ello es que no puede contemplar y aprehender intuitivamente-como ellos-la variedad de la creación. Como dice C. S. Lewis, "gozamos del intellectus cuando 'vemos simplemente'una verdad evidente» $(1980,120)$. Y esto es precisamente lo que no puede hacer el alma racional. El texto lo reitera varias veces: «la comprensión .o entorpecida! con la sobra de objetos (vv. 450-51); «entendimiento oo. vencido! no menos de la inmensa muchedumbre! de tanta maquinosa pesadumbre» (vv. 469-71).

Sor Juana recurre a otra analogía para comunicar esto: el deslumbramiento de la luz solar sobre los ojos acostumbrados a la oscuridad (vv. 495-515). Esta sección parece ser una clara alusión a la alegoría platónica de la caverna ( $L a$ República, Libro VII, 514A-521B). Como se recordará esta parábola simboliza el repentino paso del mundo de las apariencias (las sombras proyectadas sobre las paredes de la caverna parecen un primitivo antecedente de la linterna mágica) al ámbito de las formas ideales. El ascenso al mundo superior y la contemplación de las cosas de éste es similar a la ascensión del alma a la esfera inteligible, pero puede producir un efecto de desconcierto. Sócrates pregunta retóricamente: «¿no crees ... que una vez llegado a la luz, tendría los ojos tan llenos de ella que no sería capaz de ver ni una sola de las cosas a las que ahora llamamos verdaderas?» (Platón 1972, 237-38). Si tenemos presente por un momento la disposición oxímora del negro sol de la melancolía, tal como aparece èn el grabado de Durero, y la colocamos al lado del complejo simbolismo de luz y sombra del Sueño, tal vez vislumbremos algo del secreto vínculo que los une.

Después del desplome intelectual el alma se recoge «en la mental orilla» (v. 566), y recurre a la facultad discursiva de la razón. Como apunta Lewis, «ejercemos la ratio cuando avanzamos paso a paso para demostrar una verdad que no es evidente» $(1980,120)$. En efecto, el alma discurre mentalmente por 
los peldaños jerárquicos del ser, desde el «ínfimo grado / del ser inanimado» (vv. 619-20) hasta el hombre (ver figura 6), «compendio que absoluto / parece al Ángel, a la planta, al bruto» (vv. 692-93). Esta serie progresiva trae a la memoria las palabras de agradecimiento de Adán al «jerarca alado:»

Well hast thou taught the way that might direct
Qur knowledge, and the scale ofNatur,e set
From center to circumference, whereon
In contemplation of created things
By steps we ascend to God.
(Paradise Last, Libro V, 508-12)

En el pensamiento neoplatónico, el melancólico reflexivo se conduce de manera semejante en su afán de purificar su espíritu de las cosas externas. Como señala Kristeller, «Ficino interpreta esta vida contemplativa como un ascenso gradual del alma hacia grados de verdad y del ser cada vez más altos, que finalmente culmina en el conocimiento y la visión inmediatos de Dios» (1970, 65). Sin embargo, el alma del poema parece extraviarse en una digresión floral (vv. 730-56). El discurso la traiciona, «se desvía,» «se espeluza / del difícil certamen que rehusa / acometer valiente» (vv. 766-6S). Al «alto impulso» del alma, que a la manera de Faetón «determina / su nombre eternizar en su ruina» (vv. SOl-S02), lo sorprende el desperezamiento del cuerpo y la ulterior \legada de la luz.

No quisiera entrar en la polémica sobre cuál es el sentido último del poema. Paz lo ve como la revelación de la no-revelación, lo cual le da un lugar dentro de la tradición de la literatura moderna (19S3, 500). Yo sólo quisiera resaltar algunos rasgos de construcción que en vez de disminuir aumentan su complejidad semántica. El primero es la posición ambigua y precaria de la fantasía. Su capacidad de exaltación nocturna, propia del melancólico, produce infinitud de imágenes que, por así decirlo, alimentan al alma. Actuando bajo el amparo climático de la noche ( $<$ El conticinio casi ya pasando / iba, y la sombra dimidiaba,» vv.. 151-52), se le asocia con el Faro y, consecuentemente, con la luz: «cristalino portento» (v. 26S). Su contraparte estructural se encuentra hacia el final con el despertar del cuerpo, cuando la luz natural del alba está próxima a aparecer y «las fantasmas» huyen del cerebro. En esta ocasión se le compara con la linterna mágica. Este símil contrapuntista nos da pie para suponer una especie de quimérico espejismo:

la sombra fugitiva,

que en el mismo esplandor se desvanece,

cuerpo fingé fonnado,

de todas dimensiones adornado,

cuando aun ser superficie no merece.

(vv. 882-86) 
Al final aparece el sol,

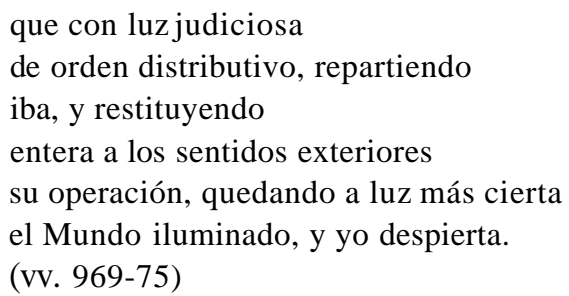

Todo este pasaje está imbuido de un espíritu jurisprudente por reintegrar todas las cosas a sus escaños jerárquicos naturales. Los últimos cuatro versos ostentan la misma trabazón poético-conceptual que encontramos al inicio de la obra: la fantasía ha bajado de su encumbramiento pasajero ahora que los sentidos externos vuelven a su actividad habitual; la claridad nocturna que mañosa representaba formas fingidas da el lugar a la «luz más cierta» del planeta luminoso; la mujer-entera, sosegada-despierta.

Mas no debemos creer que el poema privilegia la lectura solar. Los términos en que se presenta la retirada de la noche (en su mismo despeño recobrada $I$ esforzando el aliento en la ruina,» vv. 961-62), recuerda anafóricamente tanto la caída de Faetón como la del alma intelectual. El «auriga altivo del ardiente carro» (v. 787) se vuelve el prototipo del segundo intento: «ejemplar pernicioso Ique alas engendra a repetido vuelo» (vv. 804-805). Al igual que él, el alma-al verse cegada por el naufragio delintelecto-trata de ascender otra vez recurriendo a la razón.

Creo que debiéramos ver al poema como la tensión dinámica de los contrarios, que ladea alternativamente y nunca se resuelve. Esta metáfora heracliteana, que atrajo en igual medida a espíritus tan disímbolos como Jung y Paz, está de alguna manera presente en la dualidad dialéctica de los poemas de Milton a que hemos aludido antes, y en la composición que circunda a las dos estatuas de Miguel Ángel. La compensación de los opuestos también aparece implícita en el cuadrado mágico de Durero. Y esto nos remite de nuevo al planteamiento central de este ensayo: la filiación melancólica del Sueño.

Para Octavio Paz, Sor Juana Inés es melancólica desde una doble perspectiva: desde la perspectiva renacentista de Agripa y Ficino, con «<una suerte de vacuedad interior (vacantia) que ... se resolvía con una aspiración hacia lo alto;» y desde la perspectiva freudiana en que «la melancolía es un estado semejante al duelo» $(1983,286)$. Este ensayo, por su parte, ha tratado de inscribir al Sueño dentro de los modelos emblemáticos de cifrar a la melancolía. Para ello hemos puesto a dialogar a una serie de textos-incluyendo los epígrafes-muchos de los cuales eran seguramente desconocidos para nuestra poetisa, mismos que, sin embargo, nos han servido para contextualizar mejor El sueño. Quisiera terminar de la misma manera (si el lector me permite abusar aún de su 
paciencia), haciendo eco y reflejo de algo de Sir Thomas Browne, aquel extraño escritor que admiraba Borges y en el que-de algún modo--prefiguran varias de sus obsesiones nocturnas más arraigadas. Esta cita, proveniente de Religio Medici (Il, 11), resume-no sin cierto dejo de jocosidad-la tradición onírica en que se inscribe el poema de Sor Juana.

1 was bom in the planetary hour of Saturn, and 1 think 1 have a piece of that leaden planet in me. 1 am no way facetious, not disposed for the mirth and galliardize of company; yet in one dream 1 can compose a whole comedy, behold the action, apprehend the jests, and laugh my self awake at the conceits thereof. Were my memory as faithful as my reason is then fruitful, 1 would never study but in my dreams; and this time also would 1 choose for my devotion; but our grosser memories have then so little hold of our abstracted understandings that they forget the story, and can only relate to our awaked souls a confused and broken tale of that that hath passed.

Busquemos su contraparte en la Respuesta a Sor Filotea:

Sefiora mia, que ni aun el suefio se libró de este continuo movimiento de mi imaginativa; antes suele obrar en él más libre y desembarazada, confiriendo con mayor claridad y sosiego las especies que ha conservado del día, arguyendo, haciendo versos, de que os pudiera hacer un catálogo muy grande, $\mathrm{y}$ de algunas razones y delgadezas que he alcanzado dormida mejor que despierta, y las dejo por no cansaros. (Sor Juana 1957, 460) 


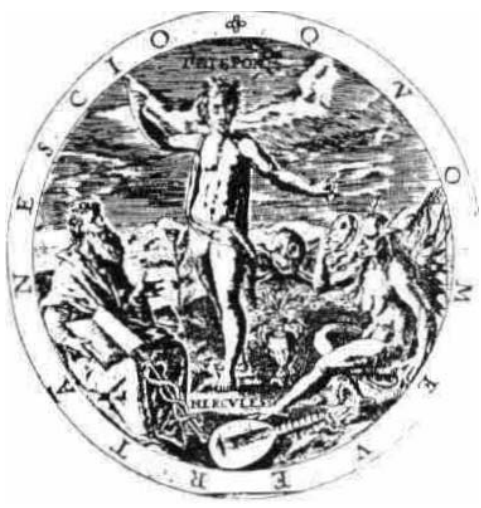

Fig, 1. George Wither. A Cul/eetian of Emblems (1635)

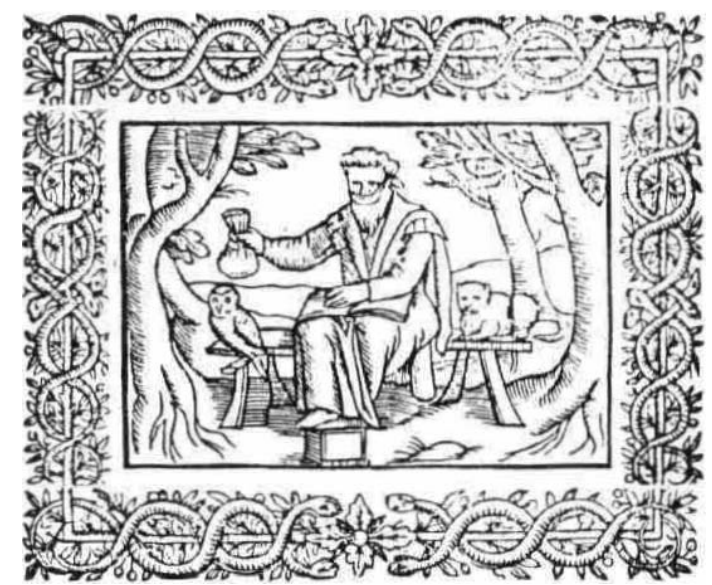

Fig 2 Melancholy. Ilenry Peacham. Minerva Britanna (16 10)

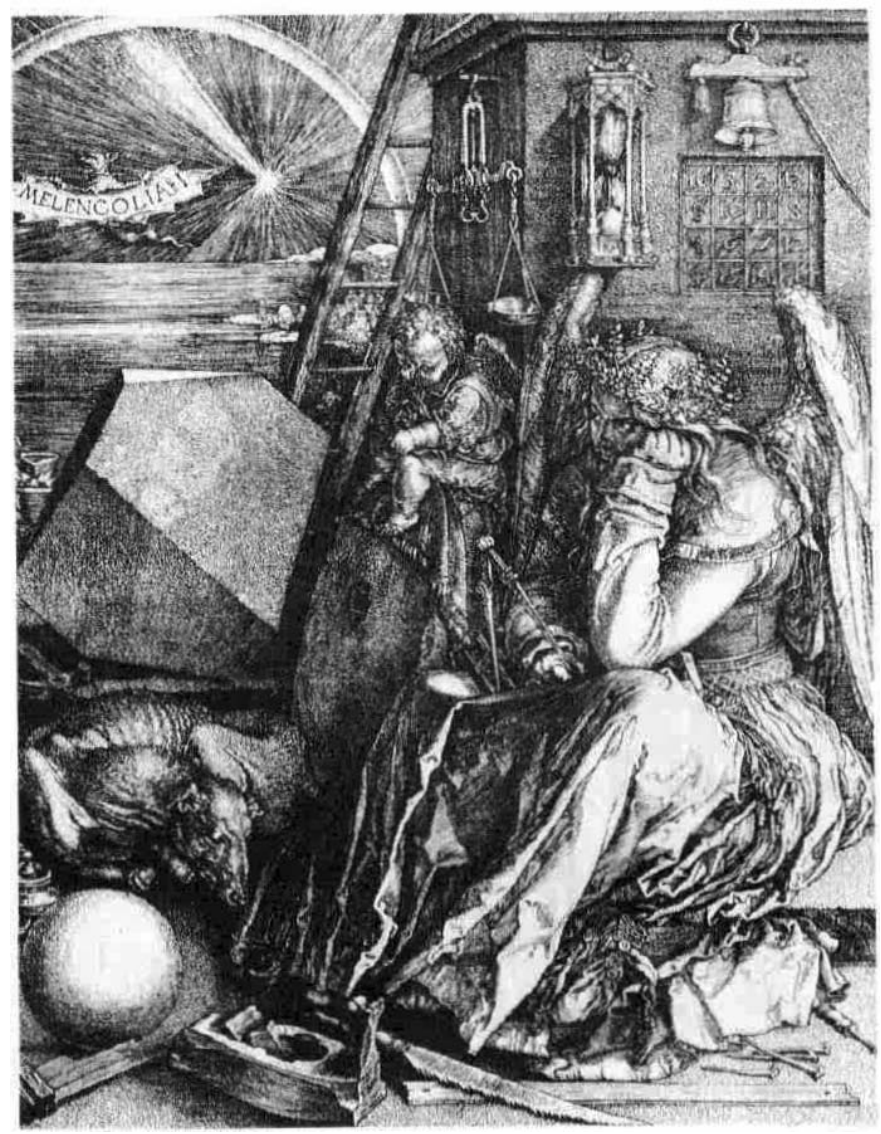

Fig. 3 Alhcnn Durcro Melencolia 1(1514) 


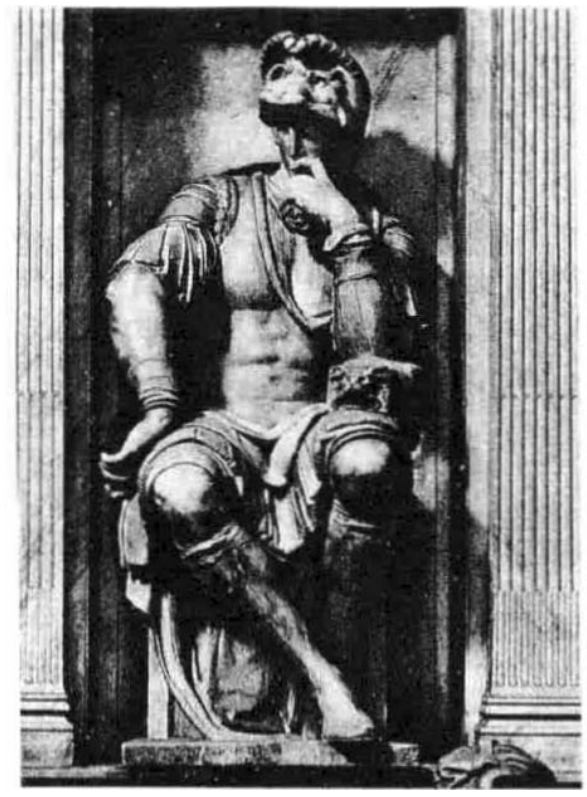

Fig 4 Miguel Ángel. Estatua de Lorenzo de Médicis

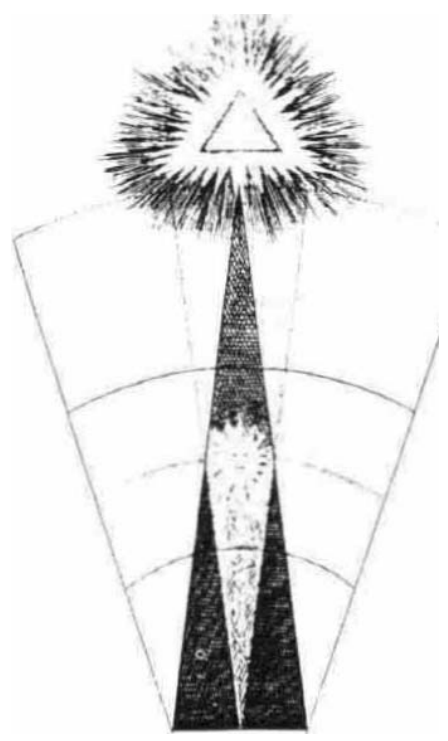

Fig 5. Pirámides de IUL. y sombra Robert Fludd Philosophia Sacra et Vere Chrutiana Seu Meterologia Cosm/cu (1626)

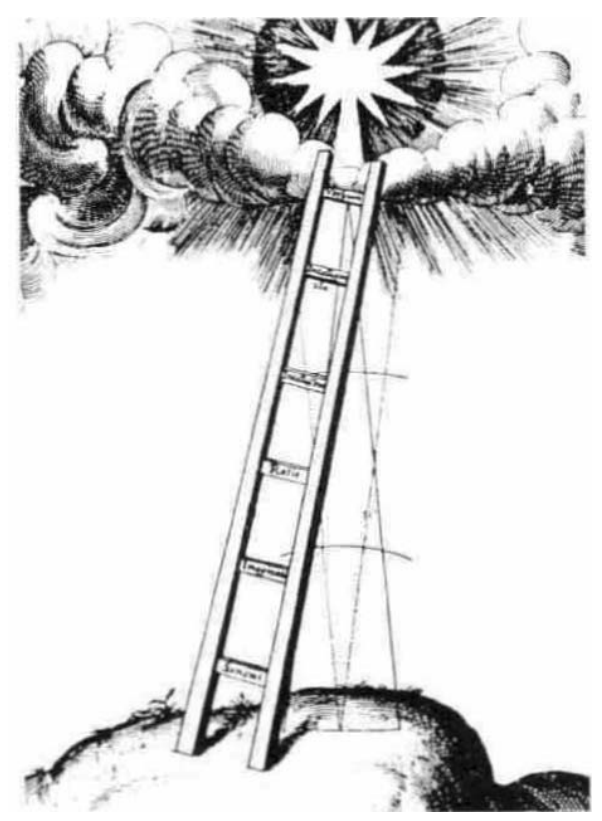

Fig 6' Escala de Jacobo Robert Fludd

Ve Supernaturali, Naturali. Preternaturali

I. rContranaturali Microcosmi / Iislona ( 1619) 


\section{Notas}

1 Hay claros indicios de esto en los villancicos de Santa Catarina, especialmente las coplas del poema 315, donde se puede leer 10 siguiente: «¿Qué mucho, si la Cruz, que por aprobio / tuvo Judea y el Romano Imperio, / entre sus jeroglíficos Egipto, / de su Serapis adoró en el pecho?»(Sor Juana 1952, 168). Paz ofrece comentarios iluminadores sobre estos villancicos y sobre la astróloga neoplatónica Hipasia de Alejandría, mencionada en la lista de mujeres célebres de la Respuesta a Sor Filotea (1983,421-27; 547-48). No olvidemos que en la Carta de Sor Filotea de la Cruz, el obispo de Puebla, Manuel Femández de Santa Cruz, se muestra muy escéptico de los logros espirituales de los egipcios, y concluye dogmáticamente: «el Espíritu Santo dice abiertamente que el pueblo de los egipcios es bárbaro» (Sor Juana 1957,695). Esto es un indicio de que el egipcianismo de Sor iuana no era bi.en visto, y que se siente acusada de revolver a los gentiles, al mostrar mayor predilección por las letras paganas que por las Sagradas Escrituras.

${ }^{2}$ He traído à còláción a la alquimia ya que en la Melencolía de Durero parece haber un atanor al extremo izquierdo del grabado, junto al poliedro irregular. No encuentro ningún comentario en Panofsky o en otros estudios iconológicos sobre dicho utensilio alquímico.

3 Méndez Plancarte presenta como posible fuente del poema el Símbolo de lafe. Fray Luis de Granada le pudo ser útil en otras partes del Sueño, mas no aquí. Para Granada hay cuatro sentidos interiores: sentido común, imaginativa, cogitativa y memoria, siendo ésta última potencia la más importante (1984, 271-74).

\section{Obras citadas}

Burton, Robert. 1932. The Anatomy ofMelancholy. 3 vols. London: Dent.

Calderón de la Barca, Pedro. 1985. El mágico prodigioso. Ed. Bruce W. Wardropper. Madrid: Cátedra.

Curtius, Erost R. 1955. Literatura europea y Edad Media latina. México: FCE.

Freeman, Rosemary. 1948. English Emblem Books. London: Chatto and Windus.

Frenk, Margit. 1966. Lírica hispánica de tipo popular. México: UNAM.

Godwin, Joscelyn. 1979. Robert Fludd. London: Thames and Hudson.

' - - . 1986. Athanasius Kircher. Madrid: Swan.

Gombrich, E. H. 1983. Imágenes simbólicas. Madrid: Alianza.

Granada, Fray Luis de. 1984. Introducción del símbolo de lafe. Ed. José María Balcells. Barcelona: Bruguera.

Hale, J. R. ed. 1981. A Concise Encyclopaedia ofthe Italian Renaissance. London: Thames and Hudson.

Huizinga, Johan. 1946. «Renacimiento y realismo.» El concepto de la historia. México: FCE.

Juana Inés de la Cruz, Sor. 1951. Obras completas. Vol. I. Líricapersonal. Ed. Alfonso Méndez Plancarte. México: FCE.

- - O 1952. Obras completas. Vol. JI. Villancicos y letras sacras. Ed. Méndez Plancarteo México: FCE.

- - O 1955. Obras completas. Vol. IJI. Autos y loas. Ed. Méndez Plancarte. México: FCE.

- - O 1957. Obras completas. Vol. IV. Comedias, sainetes y prosa. Ed. Alberto G. Salceda. México: FCE. 
Kermode, Frank and John Hollander, eds. 1973. The Oxford Anthology of English Literature. Vol. 1. New York: Oxford University Press.

Klibansky, Rayrnond, Erwin Panofsky y Fritz Saxl. 1991. Saturno y melancolía. Madrid: Alianza.

Kristeller, P. O. 1970. Ochofilósofos del Renacimiento italiano. México: FCE.

Lewis, C. S. 1980. La imagen del mundo. Barcelona: Antoni Bosch.

Martínez de Toledo, Alfonso. 1981. Archipreste de Talavera o Corbacho. Ed. Michael Gerli. Madrid: Cátedra.

Montero Vallejo, Manuel. 1975. «Introducción.» Alciato:Emblemas. Madrid: Editora Nacional.

Panofsky, Erwin. 1972. Estudios sobre iconología. Madrid: Alianza.

Pascual Buxó, José. 1984. Lasfiguraciones del sentido. México: FCE.

Paz, Octavio. 1983. Sor Juana Inés de la Cruz o las trampas de lafe. 3 a ed. México: FCE.

Platón. 1972. La República. México: UNAM.

Plotino. 1980. Selección de las Enéadas. México: Ateneo.

Seznec, Jean. 1972. The Survival ofthe Pagan Gods. Princeton: Princeton University Press.

Wittkower, Rudolf. 1977. Allegory and the Migration ofSymbols. London: Tharnes and Hudson.

Yates, Frances A. 1982. Lafilosofia oculta en la época isabelina. México: FCE. 